Proceedings of the 2011 Winter Simulation Conference

S. Jain, R.R. Creasy, J. Himmelspach, K.P. White, and M. Fu, eds.

\title{
SHAPING SENIOR LEADER OFFICER TALENT: USING A MULTI-DIMENSIONAL MODEL OF TALENT TO ANALYZE THE EFFECT OF PERSONNEL MANAGEMENT DECISIONS AND ATTRITION ON THE FLOW OF ARMY OFFICER TALENT THROUGHOUT THE OFFICER CAREER MODEL
}

\author{
Matthew F. Dabkowski \\ United States Army \\ Training \& Doctrine Command Analysis Center \\ Fort Leavenworth, K.S. 66027 \\ Paul Kucik, PhD \\ Department of Systems Engineering \\ United States Military Academy \\ West Point, N.Y. 10996
}

\author{
Samuel H. Huddleston \\ Department of Systems \& Information Engineering \\ University of Virginia \\ Charlottesville, V.A. 22904 \\ David S. Lyle, $\mathrm{PhD}$ \\ Department of Social Sciences \\ United States Military Academy \\ West Point, N.Y. 10996
}

\begin{abstract}
Army Officer requirements for operational talent decline precipitously with increasing rank. While 80 percent of Junior Officers serve in operational billets, only 20 percent of Senior Leaders serve in operational billets. Yet despite this operational talent requirement inversion, Army development efforts tend to focus disproportionately on building operational talent. Moreover, career progression through the rank of General Officer tends to excessively favor officers who have spent most of their career in operational billets. By opening additional opportunities for officers who serve outside of operational billets to reach senior leader ranks, and by exposing more officers to opportunities that develop non-operational talents, the Army can mitigate against talent gaps at senior ranks. This analysis employs discrete event simulation to quantify the extent to which attrition, promotion, and the dynamically changing need for two types of talent (operational and non-operational) impact the distribution of talent available across the Army's officer ranks.
\end{abstract}

\section{INTRODUCTION}

Army officer requirements are vast and varied. From ambushing enemy forces, securing key terrain, counseling soldiers, managing dynamic budgets, to working with the media, Army officers must perform a wide array of missions. While 80 percent of junior officers spend most of their formative years serving in standard operational or troop-leading billets, less than 20 percent of Senior Army Leaders (Colonel and above) serve in operational billets. Rather, as officers progress in rank, they disproportionately spend time in non-operational billets working on the business side of the Army. Examples of non-operational requirements include recruiting, development, program management, and force structure efforts.

Given the Army's mission of fighting and winning our nation's wars, the Army understandably invests a great deal in the development of operational talent among its officers. Newly commissioned officers attend the Basic Officer Leader Course (BOLC) and other specialty schools such as Ranger, Airborne, and Sapper. At four years of service, officers attend a 6 month Captain's Career Course (CCC). At nine years of service, officers attend a 9-month Intermediate Level Education (ILE) course and/or specialized training for functional areas. After approximately 20 years of service, officers attend a year-long course at the War College. Despite the dwindling need for operational talent at the top of the officer ranks, ironically these courses almost exclusively focus on developing operational talent. 
Beyond the apparent mismatch between the lack of non-operational focus in development courses and the Army's increasing need for non-operational talent at senior ranks, the Army's promotion system favors officers who have spent most of their career in operational billets. Among the currently serving General Officers, approximately $70 \%$ have spent their entire careers amassing deep war fighting talents. As these officers reach the rank where their operational talents are no longer in demand, they find significant gaps between their talent and what is demanded from them in the predominance of largely nonoperational billets. A General Officer recently opened a meeting with the following remark, "I have spent my entire career with troops. I have no idea why the Army assigned me to this position. I'm looking to you guys, the experts, for help in making these tough personnel decisions." This General Officer is not alone in his sentiments. The Army assigned him to this non-operational billet simply because the lionshare of billets at this rank are non-operational in nature. Favoring the advancement of officers with operational talent, focusing almost exclusively on the development of operational talent, and the high demand for non-operational talent at the senior ranks produces these talent gaps.

While the point of this paper is not to provide a normative view on how well operationally talented senior leaders perform in non-operational talent billets, it is hard to imagine a successful enterprise that would entrust executive level responsibilities to individuals who have not been developed to perform these requirements. Few would argue, to include the General Officers themselves, that the Army clearly has not developed its senior leaders to serve in these important positions. From accessing new Soldiers and officers into the Army, competing with other branches of service in the military to secure scarce resources, to conducting the business of running an Army, the Army requires critical non-operational talent.

\section{BACKGROUND}

\subsection{The Structure Problem - Career Paths and Requirements Mismatch}

The Army commissions most of its officers into one of sixteen Army competitive category branches such as infantry, armor, engineers, aviation, finance, and transportation. Historically, the Army has managed its officer talent through this taxonomy of branches. Upon completion of company command, officers can remain in one of these branches, or seek an assignment in a career field. Regardless of whether officers remain in a branch or designate into a career field, they are available to fill both operational and nonoperational assignments. However, officers who career field designate (CFD) are much less likely to serve in operational billets than officers who remain in their basic branch.

We define operational billets as any billet that primarily requires warfighting talents and we define non-operational billets as any billet that requires talents that are not directly related to warfighting. For ease of classification, we break officer billets into operational and non-operational by virtue of their accounting source. Officer billets derived from the Modified Table of Organization and Equipment (MTOE) are considered operational, while officer billets derived from the Table of Distribution and Allowances (TDA) are considered non-operational.

The fact that nearly 70 percent of all currently serving General Officers have spent the majority of their career in operational billets suggests that there is a fairly narrow pathway to General Officer ranks. The Army's career model does not tend to reward those officers who serve in non-operational billets. Panel A in Figure 1 below depicts the current state of officer career progression. The best way to make it to the top is to seek operational assignments and develop very deep warfighting talents. Even if every officer desired to serve in strictly operational assignments, Panel B shows that the Army requires more officers to fill non-operational jobs as rank increases.

For example, above the grade of Major, more than half of all assignments are non-operational in nature. For senior leaders in the rank of Colonel and above, more than three-quarters of all assignments are in non-operational billets. The confluence of the Army's career progression model in Panel A and the reality of mission requirements shown in Panel B produces this unnecessary tension. The career progression model clearly incentivizes officers to serve in operational billets, even though these billets are increasingly scarce as officers progress in rank. The officers who are successful in reaching the senior ranks of Gen- 
eral Officer have also spent most of their careers developing deep operational talent. Yet when they become senior leaders, they must serve in non-operational billets where they lack the commensurate talents.
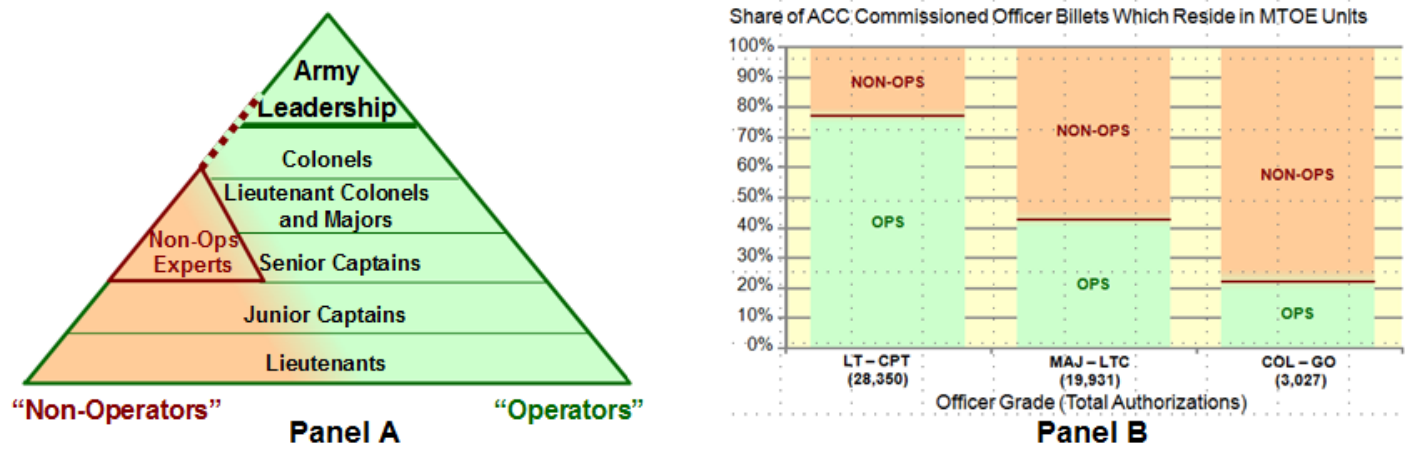

Figure 1: Operational and non-operational career paths and requirements.

\subsection{The Attrition Problem - Requirements and Inventory Imbalances}

In addition to the non-operational talent gaps at senior ranks, the Army also faces a general imbalance between personnel requirements and inventory. As our 2010 WSC paper "Shaping Senior Leader Officer Talent: How Personnel Management Decisions and Attrition Impact the Flow of Army Officer Talent Throughout the Officer Career Model" detailed, high rates of officer attrition and the inability to access mid-career officers has caused a persistent personnel shortage at the mid-career ranks. Beginning with officers accessed in the mid 1980s, the Army only retains 40 percent on active duty through eight years of service. Depending on the level of talent that departs, losing 60 percent of a cohort can have significant implications for the pool of talent available to serve as senior leaders.

To illustrate this graphically, Figure 2 traces the actual attrition and promotion patterns that occurred for year group 1986, which is one of the most recent year groups to have completed all of its selection boards through the rank of Colonel. Each pool represents one rank. At each rank through the rank of Major, attrition occurs first, promotion occurs second, and officers not selected for promotion depart. Beyond the rank of Major, some officers not selected may continue to serve. As a result of attrition occurring prior to selection for promotion, there is a reduction in the number of officers available for promotion, thereby increasing promotion rates. Had there been no attrition in the Lieutenant ranks, the effective promotion rate to Captain would have been 66 percent, some 31 points lower than the 97 percent of officers who remained on active duty through the Captain's board. This pattern repeats across all ranks, undermining the Army's ability to select its talent and forcing it to settle for its talent instead. For the past five years, promotion rates have been above 90 percent through Lieutenant Colonel.

Due to analytical intractability, our previous paper used discrete event simulation to quantify the likely impacts of attrition on the distribution of Army officer talent at various ranks. We examined three scenarios: a scenario with no attrition, a scenario where the likelihood of an individual departing is not affected by level of talent, and a scenario where higher levels of talent increase the officer's likelihood of departing. We assumed that everyone has talent, it can be measured, boards perfectly recognize talent, higher talent is selected over lower talent, and that talent is distributed normally with a mean of 50 and a standard deviation of 13. Even with these conservative assumptions, the mean talent scores for Colonel were 62 in the uniform departure scenario and 52 in the scenario where the more talented officers tend to get out at higher rates. (Dabkowski et al. 2010) These talent scores are significantly lower than the mean score of 74 that results when there is no departure. (Dabkowski et al. 2010) Even with fairly conservative assumptions, the affect of attrition on the level of talent at the rank of Colonel was significant.

Ultimately, restrictions to lateral entry into the mid and senior officer ranks, low officer retention that began in the mid1980s, and the need to fill senior officer billets have pushed promotion rates for ranks 
through Lieutenant Colonel above 90\%. At these levels, the Army loses discretion over its vetting and culling mechanisms required to shape and prune its talent pool through senior ranks.

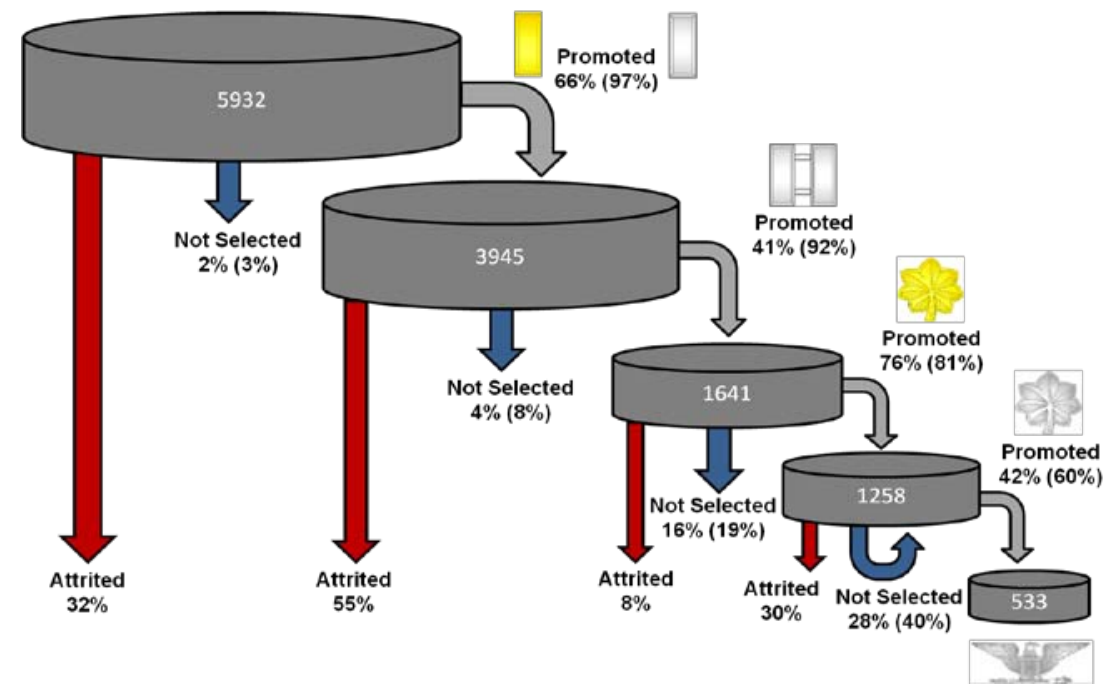

Figure 2: Officer flow model for 1986 Cohort Year Group.

\subsection{Multiple Dimensions of Talent}

Howard Gardner in his Frames of Mind: The theory of multiple intelligences, argues that a single dimension does not adequately characterize intelligence and that multiple dimensions of intelligence do not always perfectly correlate. In their paper "Multiple Intelligences of Transformational Leaders: an Empirical Examination," Hoffman and Frost analyze the effect of multiple dimensions of talent (intelligence) on aspects of transformational leadership. They define and measure three dimensions of intelligence (cognitive, social, and emotional) in members of a population of transformational leaders. While success in both operational and non-operational billets would require varying degrees of all three dimensions of intelligence (cognitive, social, and emotional), there are differences in the relative importance of each intelligence for each type of billet. For example, social intelligence may be of greater value in an operational assignment, while cognitive intelligence might benefit an officer serving in a non-operational assignment.

In addition to these studies, general human capital theory posits that everyone has a unique set of talents. This moves us beyond a discrete number of intelligences and opens the door to a limitless number of skills, knowledge, and behaviors that make each person unique (Wardynski et al. 2010). While the theory points in the direction of limitless dimensions, for modeling purposes, we focus on the different promotion and retention rates associated with two types of talent: operational and non-operational talent.

\section{SIMULATION MODEL}

\subsection{Assumptions}

As with our previous work, we used discrete event simulation to quantify the impacts of attrition and promotion rules on the Army's operational and non-operational talent. The assumptions of our model are:

- Talent: Each officer possesses operational $(X)$ and non-operational talent $(Y)$ at the start of his career, and these dimensions of talent are distributed as a bivariate normal random vector with mean 50 and standard deviation 13 in both dimensions $\left((X, Y) \sim \operatorname{BVN}\left(\mu_{X}=\mu_{Y}=50, \sigma_{X}=\sigma_{Y}=13, \rho\right)\right.$. As for the correlation coefficient $(\rho)$, Hoffman and Frost's article suggests a value around 0.5. Specifically, for the dimensions of social intelligence that (a) align closely with operational talent (i.e., team building, leadership, and oral communications) and (b) show statistically significant 
correlation with dimensions of cognitive intelligence related to non-operational talent (i.e., analysis and judgment), $\rho$ varies between 0.25 and $0.61(2006,44)$. As Figure 3 shows, when viewed in one dimension (Panels A and B), the marginal distributions of talent are simply univariate normal; $\rho$ is irrelevant. However, when viewed in the context of both dimensions (Panels $\mathrm{C}$ and D), operational talent is positively correlated with non-operational talent. Finally, while talent can be enhanced with skills and knowledge acquired throughout an officer's career, we are interested in assessing the raw talent available at the senior officer ranks. Thus, once the random variates for talent are generated, they remain constant.

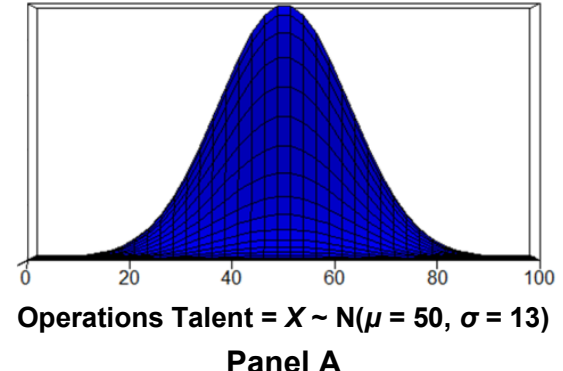

Panel A

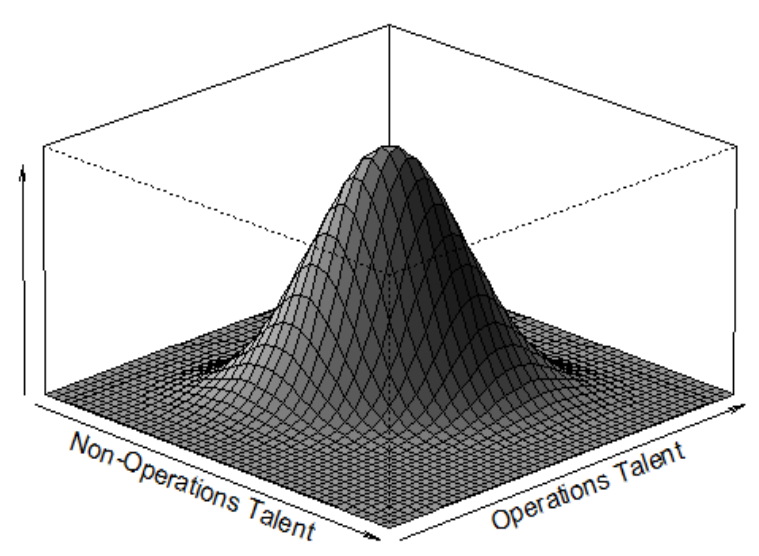

$(X, \eta) \sim \operatorname{BVN}\left(\mu_{X}=\mu_{Y}=50, \sigma_{X}=\sigma_{Y}=13, \rho=0.5\right)$

Panel C
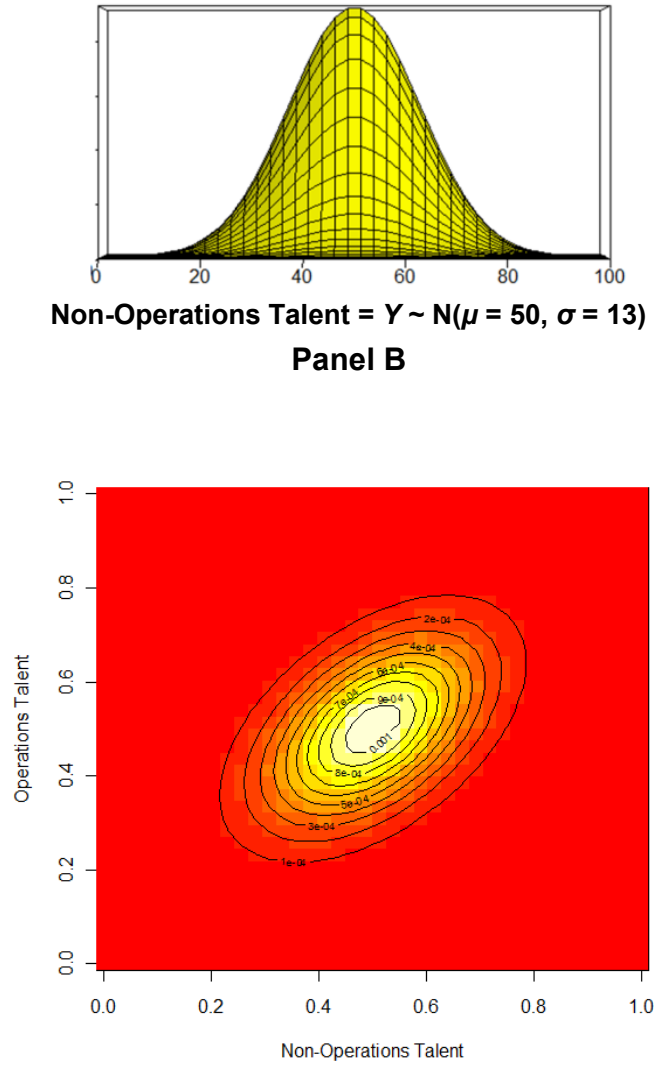

$(X, \eta) \sim \operatorname{BVN}\left(\mu_{X}=\mu_{Y}=50, \sigma_{X}=\sigma_{Y}=13, \rho=0.5\right)$

Panel D

Figure 3: Visualizing operational and non-operational talent as a bivariate normal distribution.

- Attrition: At each grade $i$, an officer receives an experience variable drawn from a uniform $(0,1)$ distribution. Figuratively, this random variate represents an officer's career satisfaction at grade $i$, and it is used to determine which officers within the cohort will leave the Army prior to their promotion board to grade $i+1$. Specifically, the officer with the smallest experience variable (e.g., least satisfaction) at grade $i$ is the first to attrit, followed by the second smallest, etc. Once the simulated attrition matches the historical attrition at grade $i$, it stops. Those officers that remain are eligible for promotion to the next higher grade.

- Promotion: Even though defining talent, let alone measuring it, is entirely conceptual at this point, we assume that the Army's promotion boards promote officers according to it and do so without error. While this assumption is clearly unrealistic, omniscient boards allow us to paint the Army's most likely state of the world in its best light, thereby strengthening our conclusions. 
Furthermore, we assume that these boards promote officers based on their operational talent only. The background material in Section 2.1 establishes the prudence of this assumption.

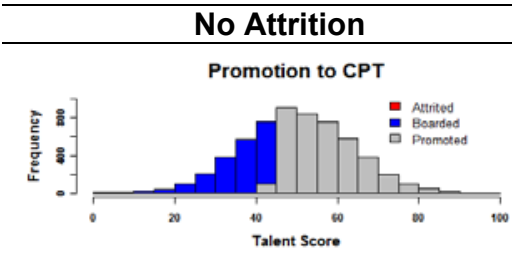

Promotion to MAJ

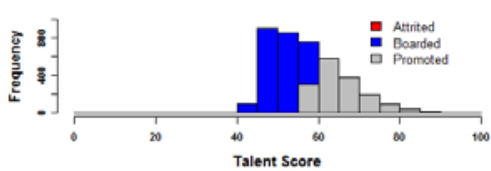

Promotion to LTC

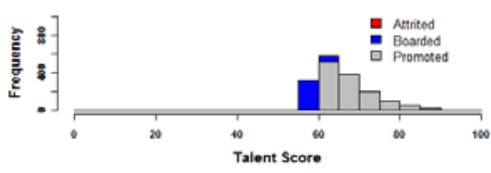

COL Promotion in Ops Dimension

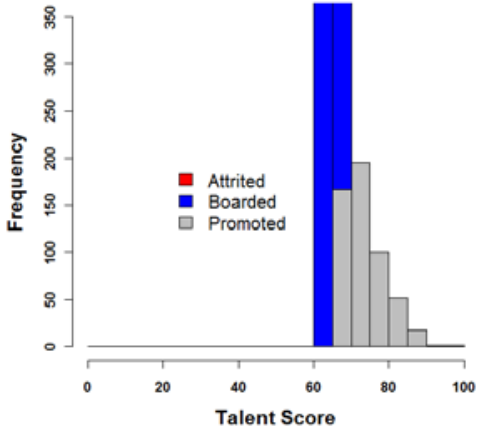

Mean $=73.6$
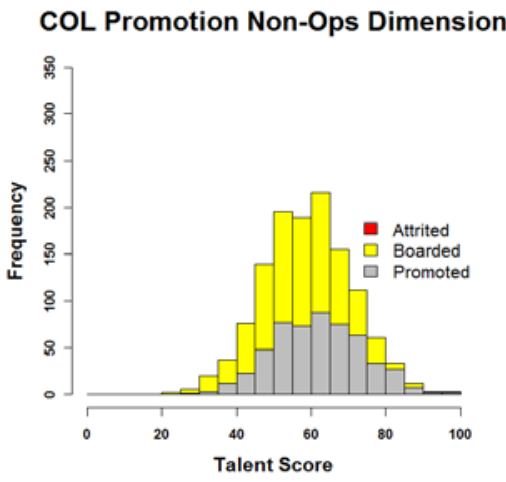

Mean $=61.8$
Uniform Attrition

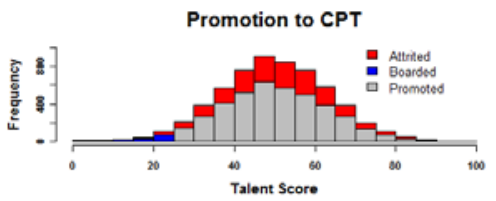

Promotion to MAJ

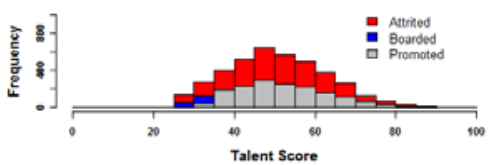

Promotion to LTC

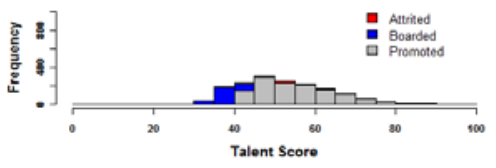

COL Promotion in Ops Dimension

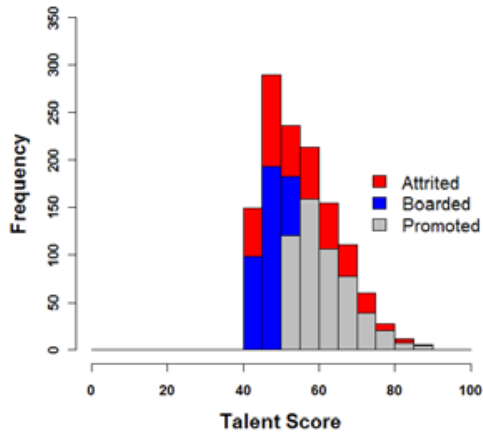

Mean $=61.4$

\section{Higher Talent, Greater Departure}

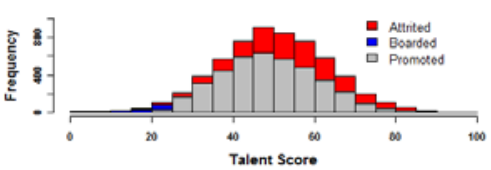

Promotion to MAJ

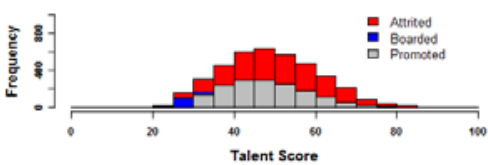

Promotion to LTC

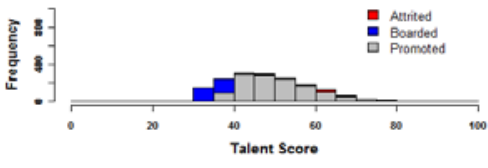

COL Promotion in Ops Dimension

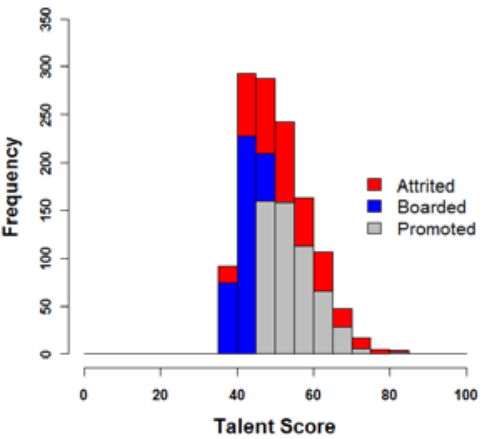

Mean $=54.6$

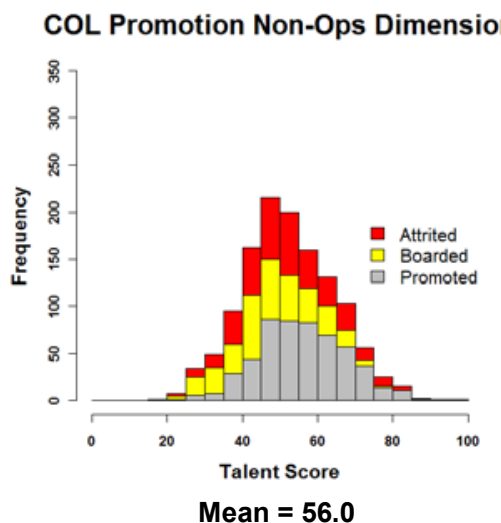

COL Promotion Non-Ops Dimension

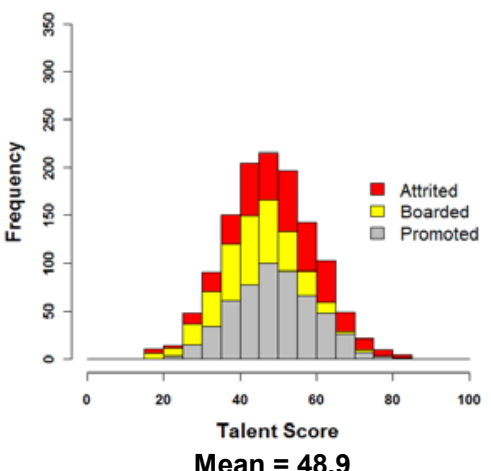

Figure 4: Results showing the simulated flow of the 1986 Cohort Year Group's talent as it advances in rank from Lieutenant (at the top) to Colonel (at the bottom) when applying the three attrition scenarios. Red portions of the histograms represent those officers who resigned before being observed by the promotion board; blue (and yellow) portions represent those officers considered for promotion; and gray portions reflect those officers selected for promotion to the indicated grade. The second-to-last and last rows reflect the distribution of operational and non-operational talent at Colonel, respectively. 


\subsection{Attrition Scenarios}

Following the design of our previous work, we analyzed the multidimensional flow of talent in three distinct attrition scenarios:

- No Attrition: In this scenario (seen in the left panel of Figure 4 on the previous page), no officers depart prior to the promotion boards. Although unrealistic, it establishes an upper bound for talent given our distribution and promotion assumptions. (Note: Order statistics provides very good, efficient approximations and validation for the No Attrition model. See the appendix for details.)

- Uniform Attrition: Given in the center panel of Figure 4, this model represents a naïve state of the world where external market forces do not attract talent. Accordingly, an officer's career satisfaction (experience variance) is not related to his talent, and officers attrit uniformly.

- Higher Talent, Greater Departure: Unlike the previous scenario, highly talented officers are more likely to attrit in this scenario. Functionally, each officer will assess his maximum talent in both dimensions against his experience variable at each grade, and those officers with the greatest delta or disappointment will leave. Based on recent articles and market surveys, this scenario is the most likely of the three (O'Keefe 2010). It is displayed in the right panel of Figure 4.

As Figure 4 clearly demonstrates, the impact of attrition on talent available to the Army at its senior ranks is severe. Specifically, as we move from left to right in the bottom two rows of the figure, the mean operational and non-operational talent for Colonels drops from 73.6 to 54.6 and 61.8 to 48.9, respectively. Put another way, attrition causes the average Colonel to look about average when compared to his original cohort. Moreover, regardless of the attrition scenario, by promoting according to operational talent only, the Army has done almost nothing to reduce the variance of its non-operational talent. Simply put, from a non-operational perspective, talent management is non-existent.

\subsection{Structure Implications}

As stated in the introduction, the vast majority of Senior Army Leaders serve in non-operational billets. In fact, at the rank of Colonel only 16 percent of the billets are operational. With this in mind, if we reasonably assume that the Army assigns its best operational talent to these operational jobs, we obtain the distributions seen in Figure 5 for our most likely scenario. While our operational talent has benefitted significantly from this assignment, rising from a mean of 54.6 to 65.8 , our non-operational talent has suffered again, sliding an additional point.
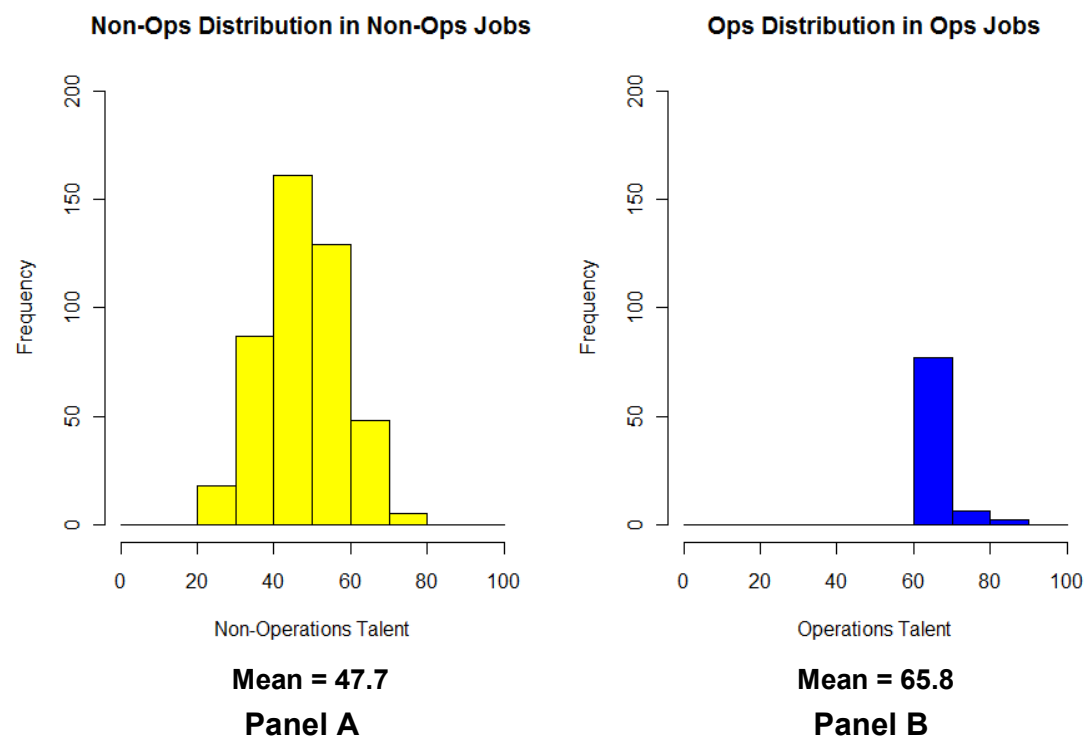

Figure 5: Talent distribution for assignments in the higher talent, greater departure scenario with $\rho=0.5$. 
Moreover, as Panel A in Figure 1 clearly shows, the path to General Officer is paved through the operational army. Accordingly, the officers portrayed in Panel B of Figure 5 effectively constitute the Army's future talent pool for its most senior ranks. With an increasingly small number of operational jobs to fill, the natural question is "Do these operators possess the requisite, raw non-operational talent to easily move into the myriad of non-operational billets?" The contour plot in Figure 6 gives us some cause for concern. Specifically, for non-operational talent the mean is 55.6 and the standard deviation is 10.5. In short, the non-operational prospects are less than optimal - over $25 \%$ of potential General Officers have below average non-operational talent.

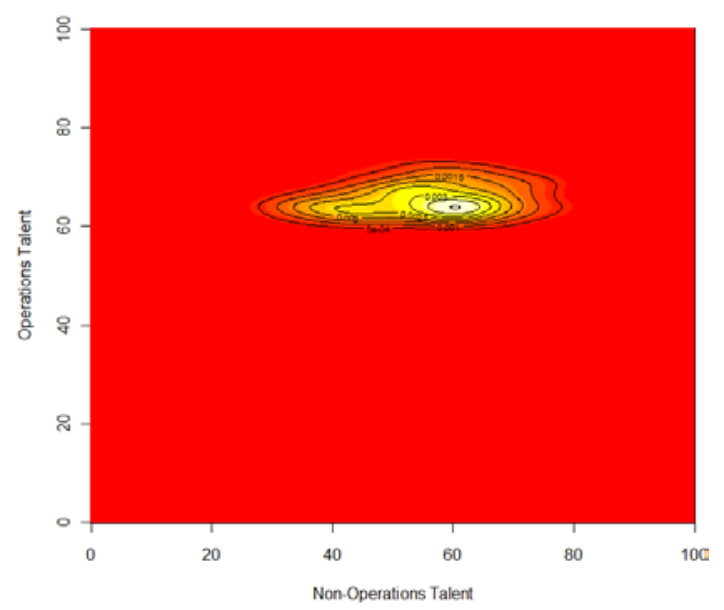

Figure 6: Overall talent distribution for COLs in operations jobs in the higher talent, greater departure scenario with $\rho=0.5$.

\section{RECOMMENDATIONS}

\subsection{Intervene at the Lieutenant Colonel Level}

While aggressively recruiting and retaining top-flight talent along both dimensions would undoubtedly provide a tremendous benefit to the Army, it is a questionable course of action. In particular, limited lateral entry and powerful market forces would necessitate wide-sweeping, prohibitively expensive incentives to ensure the best and brightest stayed in uniform long enough to advance to the highest ranks. Accordingly, what, if anything, can be done?

In our previous paper, we suggested that intervention at the Lieutenant Colonel level provided a reasonably simple approach. We echo this sentiment. Specifically, the Army currently holds its promotion board for Colonel after its Lieutenant Colonels have had the opportunity to retire from the Army with generous benefits. Suppose, however, that the Army held this board early enough in the cohort's timeline such that officers knew whether or not they would be promoted to Colonel before they could retire. This would effectively drop Lieutenant Colonel attrition prior to 20 years of service to zero. Moreover, acknowledging the need for non-operational talent in its senior ranks, suppose the Army promoted its Lieutenant Colonels to Colonel based on the maximum of both dimensions of talent.

Based on results obtained from our simulation, these two modifications would have a powerful effect. As seen in Figure 7, the mean operational talent would rise from 65.8 to 69.2, and, even more impressively, the mean non-operational talent would improve from 47.7 to 60.5 . 

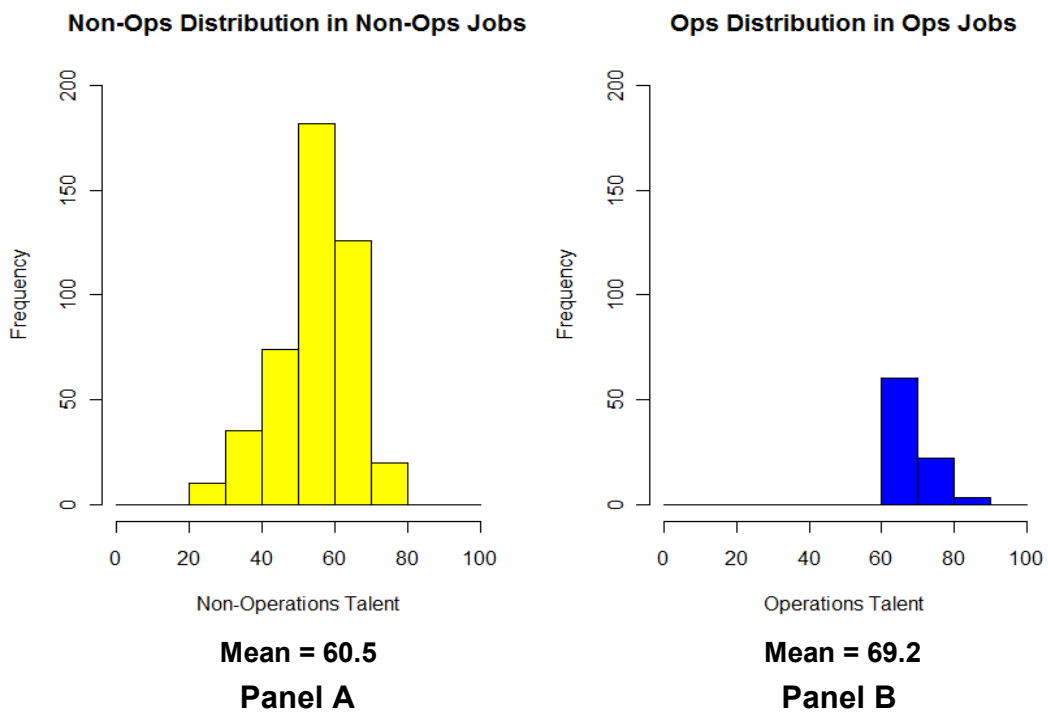

Figure 7: Talent distribution for assignments in the higher talent, greater departure scenario with $\rho=0.5$, when the Army (a) holds the Colonel promotion board early enough to eliminate Lieutenant Colonel attrition prior to the board, and (b) promotes Lieutenant Colonels to Colonel based on the maximum of both dimensions of talent.

\subsection{Align Career Paths with Requirements}

A career path model more closely aligned with actual requirements might look something like Figure 8 . In this case there are career paths that allow officers who begin developing deep non-operational talent in the midcareer ranks to progress through senior ranks. In addition to obvious retention implications, this approach affords the Army the opportunity to develop a bench of officers who possess deep nonoperational talent.

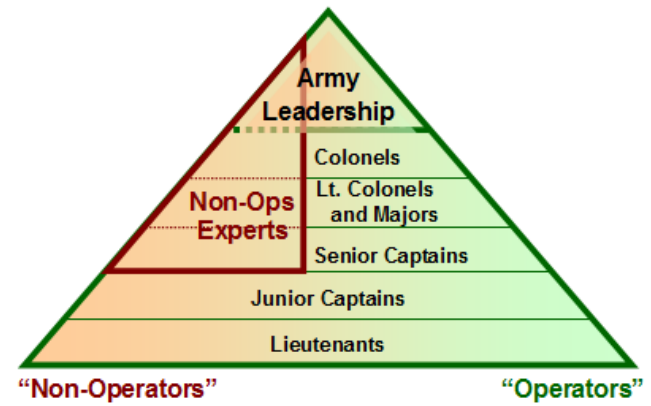

Figure 8: Career paths that align with requirements.

When the concept in Figure 8 is placed in the context of the broader officer career model that we detail in our previous paper, the implications of promotion and retention become abundantly clear. We further break the model in three phases across time. The first phase is where officers learn the profession by spending a majority of their time in operational billets. In phase 2, officers practice the profession by serving either exclusively in operational billets, exclusively in non-operational billets, or a mix of both types. As leaders of the profession, they will primarily serve in non-operational billets, but comprise a mix of broadened warfighters, expert advisors, and enterprise leaders. 


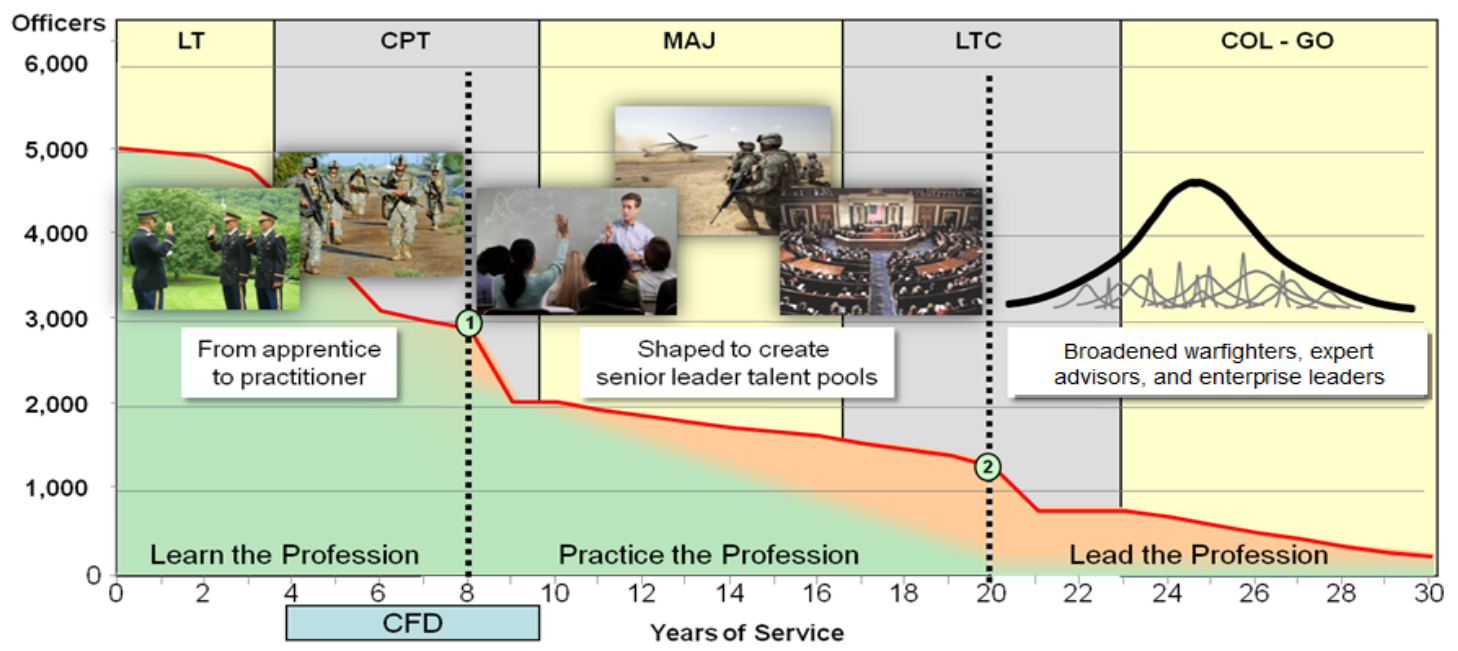

Figure 9: Operational and non-operational talent in the Officer Career Model.

The endstate of this approach is to create a robust distribution of senior leader talent that appreciates the unique talents of each senior leader, deliberately developed across a career through careful management of officer assignments. The uncertainty of the future and the ever-changing nature of Army requirements mandates this broad distribution of broadened warfighters, expert advisors, and enterprise leaders.

\section{ACKNOWLEDGMENT}

The views expressed herein are those of the authors and do not reflect the position of the United States Military Academy, the Training and Doctrine Command Analysis Center, the Department of the Army, or the Department of Defense.

\section{APPENDICES}

\section{A APPROXIMATING BUSINESS TALENT IN THE NO ATTRITION MODEL}

In our 2010 WSC paper "Shaping Senior Leader Officer Talent: How Personnel Management Decisions and Attrition Impact the Flow of Army Officer Talent Throughout the Officer Career Model," we presented a useful approximation for calculating the expected talent of the $r^{\text {th }}$ most talented officer. Specifically, in the case of a $N(0,1)$ parent distribution, the expected value of the $r^{\text {th }}$ largest observation in a sample of $n$ observations can be estimated by the following relation (David 2003, 85):

$$
\begin{aligned}
E\left[X_{r: n}\right] & =\Phi^{-1}\left(p_{r}\right)+\frac{p_{r} q_{r}}{2(n+2)}\left(\frac{\Phi^{-1}\left(p_{r}\right)}{\phi^{2}\left(\Phi^{-1}\left(p_{r}\right)\right)}\right) \\
& +\frac{p_{r} q_{r}}{(n+2)^{2}}\left[\frac{1}{3}\left(q_{r}-p_{r}\right)\left(\frac{1+2\left(\Phi^{-1}\left(p_{r}\right)\right)^{2}}{\phi^{3}\left(\Phi^{-1}\left(p_{r}\right)\right)}\right)+\frac{1}{8} q_{r} p_{r}\left(\frac{\Phi^{-1}\left(p_{r}\right)\left(7+6\left(\Phi^{-1}\left(p_{r}\right)\right)^{2}\right)}{\phi^{4}\left(\Phi^{-1}\left(p_{r}\right)\right)}\right)\right]
\end{aligned}
$$

where $p_{r}=r /(n+1), q_{r}=1-p_{r}$ and $\Phi^{-1}(\cdot)$ and $\phi(\cdot)$ are the inverse CDF and PDF of the standard normal distribution, respectively. Moreover, from the familiar standardizing relation for normal random variables, the expected talent for officers drawn from any $N(\mu, \sigma)$ parent distribution is immediately obtainable via $X=\sigma Z+\mu$, where $Z$ represents the approximation for $E\left[X_{r: n}\right]$ given in (1). 
Using the above, suppose we are interested in estimating the expected non-operational talent of the Army's least operationally-talented Colonel in YG86, recalling: (a) it accessed 5932 officers, (b) the assumed distribution of talent within this cohort is $\operatorname{BVN}\left(\mu_{X}=\mu_{Y}=50, \sigma_{X}=\sigma_{Y}=13, \rho=0.5\right.$ ), (c) the Army promoted 533 (or $8.99 \%$ ) of these officers to Colonel, and (d) the Army promotes according to operational talent only. Assuming perfect promotion boards, the expected non-operational talent of the least operationally-talented Colonel is equivalent to the expected non-operational talent of the officer with 533rd highest operational talent. In the parlance of order statistics, this is equivalent to calculating the expected value of the concomitant or $E\left[Y_{[r: n]}\right]$, where:

$$
E\left[Y_{[r: n]}\right]=\mu_{X}+\rho \sigma_{Y} \alpha_{r: n}
$$

$\alpha_{r: n}=\left(E\left[X_{r: n}\right]-\mu_{X}\right) / \sigma_{X}$, and $E\left[X_{r: n}\right]$ is given by (1) above (David 2003, 145). Setting $r=5932-533$ $+1=5400$ and $n=5932$, we obtain $E\left[Y_{[5400: 5932]}\right]=58.7237$, which compares nicely with the $95 \%$ confidence interval $(57.8071,59.2420)$ produced by 1000 Monte Carlo trials.

To be sure, quickly approximating the $r^{\text {th }}$ highest non-operational talent in the no-attrition model is useful, as it allows us to obtain the minimum, median, and maximum non-operational talent at any rank. Nonetheless, we might also be interested in estimating the mean non-operational talent, and this is equivalent to approximating the induced selection differential. Given in (3) below, the induced selection differential $\left(D_{[k, n]}\right)$ of a random sample of $n$ observations from a bivariate distribution function $F_{X, Y}$ captures the difference between the concomitant's ( $Y$ 's) mean and the average of the $Y$ 's paired with the $k$ largest values of $X$ (David 2003, 348).

$$
D_{[k, n]}=\frac{1}{k} \sum_{i=n-k+1}^{n} \frac{Y_{[i: n]}-\mu_{Y}}{\sigma_{Y}}
$$

Using a result from Nagaraja (1982) if " $\left(X_{i}, Y_{i}\right), i=1, \cdots, n$ [is] a random sample from the simple linear regression model $Y=\alpha+\beta X+E$ where $X$ and $E$ are mutually independent with finite variances, $X$ is continuous, and $\mu_{E}=0, "$ then as $k=[n p] \rightarrow \infty$ with $0<p<1$ fixed:

$$
\sqrt{k}\left\{D_{[k, n]}-\rho\left(\mu_{X}(p)-\mu_{X}\right) / \sigma_{X}\right\} \stackrel{\mathcal{L}}{\rightarrow} N(0, \cdots)
$$

where $q=1-p$ and $\mu_{X}(p)$ is the conditional mean of the distribution of $X$ when truncated below at the $q^{\text {th }}$ quantile $\left(\xi_{X}(q)=\mu_{X}+\sigma_{X} \Phi^{-1}(q)\right)(1982,260)$. In short, for $n$ (and thus $k$ ) large, the right-hand side converges in distribution to a normal distribution with mean 0. Applying the Portmanteau Lemma, which, among other things, states that the sequence of random variables $X_{n}$ converges in distribution to the random variable $X$ if and only if $E\left[f\left(X_{n}\right)\right] \stackrel{\mathcal{L}}{\rightarrow} E[f(X)]$ for all bounded, continuous functions $f$ (van der Vaart 1998, 6), we obtain:

$$
E\left[\sqrt{k}\left\{D_{[k, n]}-\rho\left(\mu_{X}(p)-\mu_{X}\right) / \sigma_{X}\right\} \stackrel{\mathcal{L}}{\rightarrow} E[N(0, \cdots)]=0 .\right.
$$

Recalling the assumed distribution of talent within this cohort is $\operatorname{BVN}\left(\mu_{X}=\mu_{Y}=50, \sigma_{X}=\sigma_{Y}=13, \rho=0.5\right)$, the marginal distribution of $X$ is $\mathrm{N}(50,13)$, thus $\mu_{X}(p)=\mu_{X}+\sigma_{X}(\phi(t) /(1-\Phi(t))$ where $t=$ $\left(\xi_{X}(q)-\mu_{X}\right) / \sigma_{X}$ (Barr and Sherrill 1999, 359). Assuming that (5) provides a reasonable approximation when $n=5932$ and $k=533$, we simplify, yielding:

$$
\begin{aligned}
E\left[D_{[k, n]}\right] & \approx \rho\left(\frac{\phi(t)}{1-\Phi(t)}\right) \\
& \approx \rho\left(\frac{\phi\left(\Phi^{-1}(q)\right)}{1-q}\right) .
\end{aligned}
$$


Substituting $q=1-533 / 5932=0.9101$ and $\rho=0.5$, we obtain $E\left[D_{[k, n]}\right]=0.9026$, which equates to 61.7332 in the concomitant's parent $\mathrm{N}(50,13)$ distribution. This result compares very favorably with the estimate obtained after 1000 Monte Carlo trials, namely: 61.7399 (with 95\% CI $(61.7071,61.7728)$ ).

\section{REFERENCES}

Barr, D. R. and E. T. Sherrill. 1999. "Mean and Variance of Truncated Normal Distributions." The American Statistician 53:357-361.

Dabkowski, M. F., S. H. Huddleston, P. Kucik, and D. Lyle. 2010. "Shaping Senior Leader Officer Talent: How Personnel Management Decisions and Attrition Impact the Flow of Army Officer Talent Throughout the Officer Career Model." In Proceedings of the 2010 Winter Simulation Conference, edited by B. Johansson, S. Jain, J. Montoya-Torres, J. Hugan, and E. Yücesan, 1407-1418. Piscataway, New Jersey: Institute of Electrical and Electronics Engineers, Inc.

David, H. A. and H. N. Nagaraja. 2003. Order Statistics. 3rd ed. John Wiley \& Sons, Inc.

Hoffman, B. and B. Frost. 2006. "Multiple Intelligences of Transformational Leaders: an Empirical Examination." International Journal of Manpower, 27:37-51.

Nagaraja, H. N. 1982. "Some Asymptotic Results for the Induced Selection Differential." Journal of Applied Probability 19:253-261.

O'Keefe, B. 2010. "Meet the New Face of Business Leadership." Fortune 161(4).

van der Vaart, A. W. 1998. Asymptotic statistics. Cambridge University Press.

Wardynski, Lyle, and Colarusso. 2010. "Towards a U.S. Army Officer Corps Strategy, Talent: Implications for a U.S. Army Officer Corps Strategy." Strategic Studies Institute, U.S. Army War College, Volume 2.

\section{AUTHOR BIOGRAPHIES}

MATTHEW DABKOWSKI is an Operations Research Analyst at the Training and Doctrine Command Analysis Center at Fort Leavenworth Kansas. He holds an M.S. in Systems Engineering from the University of Arizona and a B.S. is in Operations Research from the United States Military Academy. His research interests include multiple objective decision making, applied statistics, and simulation modeling. His email address is $<$ matthew.dabkowski@us.army.mil $>$.

SAMUEL H. HUDDLESTON is currently pursuing a Ph.D. in Systems and Information Engineering from The University of Virginia. He holds a Master of Science in Systems and Information Engineering from The University of Virginia and a Bachelors of Science from the United States Military Academy. His research interests include statistical learning, counter-terrorism, agent-based simulation and network analysis. His email address is <samuel.huddleston@usma.edu>.

PAUL KUCIK is the Director of the Operations Research Center of Excellence, United States Military Academy at West Point. He holds a Ph.D. in Management Science and Engineering from Stanford University, an MBA from the Massachusetts Institute of Technology, and a B.S. in Economics from the United States Military Academy. His research interests include decision analysis, risk analysis, economics, counterinsurgency, and simulation modeling. His email address is<paul.kucik@usma.edu>.

DAVID LYLE is an Associate Professor of Economics and the Deputy Director of the Office of Economic and Manpower Analysis, United States Military Academy at West Point. He holds a Ph.D. in Economics from the Massachusetts Institute of Technology, and a B.S. in Economics from the United States Military Academy. His research interests include labor economics, human capital theory, peer effects, economics of national defense, and econometrics. His email address is <david.lyle@usma.edu>. 